\title{
DYNAMIC BEHAVIOR OF VARIABLE SPEED PUMP STORAGE UNITS IN THE GERMAN ELECTRIC POWER SYSTEM
}

\author{
I. Erlich*, U. Bachmann** \\ *Department of Electrical Power Systems, University of Duisburg, \\ Bismarckstr.81,D-47048Duisburg,Germany,erlich@uni-duisburg.de \\ **Vereinigte Energiewerke AG VEAG,D-12631Berlin, Germany,udbachmann@veag.de
}

\begin{abstract}
This paper reports about simulation studies carried out in connection with the new pump storage power plant Goldisthal of the German power company VEAG. Two units are equipped with double fed induction machine drives and thus, they are able to vary the speed. A simulation model was developed to investigate the dynamic behavior of the units in interaction with the power system. As a result of a systematic multivariable controller design, active and reactive power control channels are decoupled. The controller used in this study shows a Dead-Beat-behavior. A special feature of the controller is its ability to compensate terminal voltage changes. Simulation results in a model of the German and European Interconnected Power System demonstrate the control capabilities of the variable speed units. Copyright (C) 2002 IFAC
\end{abstract}

Keywords: Adjustable Speed Generation Systems, Double Fed Machine, Multivariable Control, Pump Storage Power Plant, Power System Simulation.

\section{INTRODUCTION}

The new pump storage power plant called "Goldisthal" of the German electric power company VEAG will have a total capacity of $1060 \mathrm{MW}$. Goldisthal is located in the southern region of the VEAG network in the province Thuringia. The first one of the four units will go in operation at the end of 2002. Two of them will be build with double fed induction machines (DFIM), which are able to vary the rotor speed in a restricted range of 300 to 347 rpm. The nominal power of these variable speed machines is $267 \mathrm{MW}$. The rotors of DFIM drives are equipped with three-phase windings and fed via frequency converter. The mechanical speed is the result of the superposition of both stator and rotor rotating magnetic fields and thus variable depending on the frequencies of supply. Because the required converter power is determined by the maximal rotor speed difference relating to the synchronous speed, the restriction of speed variability results in a smaller and chipper converter. For the Goldisthal machines, the required converter rated power is approximately 50 MVA. The variable speed technique with DFIM provides several advantages for pump storage power plants:
- The units are able to operate in part load pump mode (Bogenrieder, 2000)

- It is possible to adjust the speed to the actual water head

- Active and reactive power as well can be controlled in a quick manner electronically.

This means a higher efficiency and thus more flexibility in operation. Both issues are very important in the competitive German electricity market.

The power plant Goldisthal is connected to a network via a $380-\mathrm{kV}$ double circuit tie line. Resulting from the large power and the control capabilities, Goldisthal can influence the dynamic behavior of the whole system considerably. In this paper, we will report about:

- Modeling of DFIM for the simulation of power system dynamics in multi-machine systems in the frequency range of $0.1-10 \mathrm{~Hz}$

- Systematic multivariable controller design to decouple active and reactive power control channels

- The control schemes in generator- and pumpmodes

- Simulation results carried out in a representative network 


\section{MODELING OF DOUBLE FED INDUCTION MACHINES}

Electromechanical oscillations in the frequency range of $0.1-10 \mathrm{~Hz}$ are physically caused by the changes of the kinetic and magnetic energy stored in the rotor. The low frequencies allow the use of reduced order system models and thus the simulation of large electric power systems. The basic reduction results from the neglecting of the transformer terms in the stator voltage equations (Kundur, 1994). That means that the stator circuits and consequently the whole network can be modeled by algebraic equations.

The machine is fully described by the equations (1)(5), where complex per-unit quantities and spacephasor variables are used. The upper index $\angle \mathrm{K}$ describes the rotating orthogonal reference frame not specified yet.

$$
\begin{aligned}
& \underline{\mathrm{u}}_{\mathrm{S}}^{\angle \mathrm{K}}=\mathrm{r}_{\mathrm{S}} \cdot \underline{\underline{S}}_{\mathrm{S}}^{\angle \mathrm{K}}+\frac{\mathrm{d} \underline{\Psi}_{\mathrm{S}}^{\angle \mathrm{K}}}{\mathrm{dt}}+\mathrm{j} \cdot \omega_{\mathrm{K}} \cdot \underline{\Psi}_{\mathrm{S}}^{\angle \mathrm{K}} \\
& \underline{\mathrm{u}}_{\mathrm{R}}^{\angle \mathrm{K}}=\mathrm{r}_{\mathrm{R}} \cdot \dot{\mathrm{i}}_{\mathrm{R}}^{\angle \mathrm{K}}+\frac{\mathrm{d} \underline{\psi}_{\mathrm{R}}^{\angle \mathrm{K}}}{\mathrm{dt}}+\mathrm{j} \cdot\left(\omega_{\mathrm{K}}-\omega_{\mathrm{R}}\right) \cdot \underline{\Psi}_{\mathrm{R}}^{\angle \mathrm{K}} \\
& \underline{\psi}_{\mathrm{S}}^{\angle \mathrm{K}}=1_{\mathrm{S}} \cdot \underline{\mathrm{i}}_{\mathrm{S}}^{\angle \mathrm{K}}+1_{\mathrm{h}} \cdot \underline{\mathrm{i}}_{\mathrm{R}}^{\angle \mathrm{K}} \\
& \underline{\Psi}_{\mathrm{R}}^{\angle \mathrm{K}}=1_{\mathrm{h}} \cdot \underline{\mathrm{i}}_{\mathrm{S}}^{\angle \mathrm{K}}+1_{\mathrm{R}} \cdot \underline{\mathrm{i}}_{\mathrm{R}}^{\angle \mathrm{K}} \\
& \frac{\mathrm{d} \omega_{\mathrm{R}}}{\mathrm{dt}}=\frac{1}{\mathrm{~T}_{\mathrm{m}}}\left(\mathrm{m}_{\mathrm{T}}+\psi_{\mathrm{Sd}} \mathrm{i}_{\mathrm{Sq}}-\psi_{\mathrm{Sq}} \mathrm{i}_{\mathrm{Sd}}\right)
\end{aligned}
$$

Neglecting stator transients means, that

$$
\frac{\mathrm{d} \underline{\mathrm{S}}_{\mathrm{S}}^{\angle \omega_{0}}}{\mathrm{dt}}=0
$$

will be set in the voltage equation (1), whereas this step is done in the synchronously rotating $\angle \omega_{0}$-reference frame. The theoretical background of this model reduction is discussed in (Erlich, 1995). After some algebraic manipulation, we get the state equations (7), (8).

$\frac{\mathrm{d} \underline{\Psi}_{R}^{\angle K}}{\mathrm{dt}}=-\left(\underline{T}_{L 0}^{-1}+\frac{\mathrm{j} \cdot \omega_{0} \cdot k_{R}^{2} \cdot r_{R}}{\underline{z}}\right) \cdot \underline{\Psi}_{R}^{\angle K}+\frac{r_{R} \cdot k_{R}}{\underline{z}} \cdot \underline{u}_{S}^{\angle K}+\underline{u}_{R}^{\angle K}$

$\frac{\mathrm{d} \omega_{\mathrm{R}}}{\mathrm{dt}}=\frac{1}{\mathrm{~T}_{\mathrm{m}}}\left(\mathrm{m}_{\mathrm{T}}+\psi_{\mathrm{Rd}} \mathrm{i}_{\mathrm{Sq}}-\psi_{\mathrm{Rq}} \mathrm{i}_{\mathrm{Sd}}\right)$

with

$\underline{T}_{L 0}^{-1}=\frac{r_{R}}{1_{R}}+j \cdot\left(\omega_{K}-\omega_{R}\right)$

$\mathrm{k}_{\mathrm{R}}=\frac{\mathrm{l}_{\mathrm{h}}}{\mathrm{l}_{\mathrm{h}}+\mathrm{l}_{\sigma \mathrm{R}}}$

The coupling of the dynamic model part with the static network is described by the algebraic equation

$\underline{i}_{\mathrm{S}}^{\angle \mathrm{K}}=\frac{\underline{\mathrm{u}}_{\mathrm{S}}^{\angle \mathrm{K}}-\mathrm{j} \omega_{0} \mathrm{k}_{\mathrm{R}} \underline{\psi}_{\mathrm{R}}^{\angle \mathrm{K}}}{\left(\mathrm{r}_{\mathrm{S}}+\mathrm{j} \omega_{0}{ }^{1}\right)}$

where the stator current is used again. The transient inductance $l^{\prime}$ is defined as follows: $1^{\prime}=1_{h}+1_{\sigma S}-\frac{1_{h}^{2}}{1_{h}+1_{\text {oR }}}$

It is possible to introduce a transient driving voltage

$\underline{\mathrm{u}}^{\prime}=\mathrm{j} \omega_{0} \mathrm{k}_{\mathrm{R}} \underline{\Psi}_{\mathrm{R}}^{\angle \mathrm{K}}$

which is a function of rotor flux linkages and acting behind the transient impedance

$\left.\underline{z^{\prime}}=\left(\mathrm{r}_{\mathrm{S}}+\mathrm{j} \omega_{0}{ }^{\prime}\right)^{\prime}\right)$

For solving the algebraic network equations, it is favorably to use driving currents instead of driving voltages. It is defined by Equation (15)

$\underline{i}^{\prime}=-\frac{\underline{u}}{\underline{z^{\prime}}}$

The solution of the DFIM equations in interaction with other synchronous and asynchronous machines in the network and the network solution itself, proceeds as follows: solving the differential equations for a time increment $\Delta \mathrm{t} \rightarrow$ setting the driving currents to the terminal nodes $\rightarrow$ solving the algebraic network equations which result in all node voltages $\rightarrow$ solving the differential equations for a new time step.

The state equations (7) and (8) comprise the rotor flux linkage $\underline{\Psi}_{R}^{2}$ and the rotor speed $\omega_{R}$ as state variable, the rotor voltage $\underline{\underline{u}}_{R}^{\angle K}$ as input variable, and the stator voltage $\underline{u}_{s}^{\mathcal{K}}$, which is interpreted as disturbance variable. The basic difference of this model compared with the classical asynchronous motors is the assumption of a complex rotor voltage. Using these, it is possible to control of two different motor quantities.

\section{MULTIVARIABLE CONTROLLER DESIGN}

For a better handling, the state equations (7) and (8) should be written in the following discrete vectors form

$$
\boldsymbol{\Psi}_{\mathrm{R}}^{\angle \mathrm{K}}(\mathrm{k}+1)=\boldsymbol{\Phi}\left(\omega_{\mathrm{R}}, \omega_{\mathrm{K}}\right) \cdot \boldsymbol{\Psi}_{\mathrm{R}}^{\angle \mathrm{K}}(\mathrm{k})+\mathbf{H} \cdot \mathbf{u}_{\mathrm{R}}^{\angle \mathrm{K}}(\mathrm{k})+\mathbf{h} \cdot \mathbf{u}_{\mathrm{S}}^{\angle \mathrm{K}}(\mathrm{k})
$$

With the control approach

$\mathbf{u}_{\mathrm{R}}^{\angle \mathrm{K}}(\mathrm{k})=\mathbf{H}^{-1} \cdot\left|\mathbf{y}^{\angle \mathrm{K}}(\mathrm{k}-1)-\mathbf{h} \cdot \mathbf{u}_{\mathrm{s}}^{\angle \mathrm{K}}(\mathrm{k})\right|$

where $\mathbf{y}^{\angle K}$ is the output of the regulator, it is possible to compensate the disturbance variables $\mathbf{u}_{\mathrm{S}} \mathrm{K}(\mathrm{k})$ (Quang,1999). This is obvious by substituting $\mathbf{u}_{\mathrm{R}}^{\angle \mathrm{K}}(\mathrm{k})$ in Equation (16)

$\boldsymbol{\Psi}_{\mathrm{R}}^{\angle \mathrm{K}}(\mathrm{k}+1)=\boldsymbol{\Phi}\left(\omega_{\mathrm{R}}, \omega_{\mathrm{K}}\right) \cdot \boldsymbol{\Psi}_{\mathrm{R}}^{\angle \mathrm{K}}(\mathrm{k})+\cdot \mathbf{y}^{\angle \mathrm{K}}(\mathrm{k}-1)$

and z-transformed:

$(z \mathbf{I}-\mathbf{\Phi}) \cdot \mathbf{\Psi}_{R}^{\angle K}(z)=z^{-1} \cdot \mathbf{y}^{\angle K}(z)$

The approach for the control equation is now

$\mathbf{y}^{\angle \mathrm{K}}(\mathrm{z})=\mathbf{R} \cdot\left(\boldsymbol{\Psi}_{\mathrm{R}}^{*} \angle \mathrm{K}(\mathrm{z})-\boldsymbol{\Psi}_{\mathrm{R}}^{\angle \mathrm{K}}(\mathrm{z})\right)$

where $\mathbf{R}$ is the controller matrix and $\boldsymbol{\Psi}_{\mathrm{R}}^{* \alpha \mathrm{K}}(\mathrm{z})$ the reference value of the controlled variable, which is a vector of rotor flux linkages. The setup of $\mathbf{R}$ depends on the target function that the controller has to meet. 
We have realized a controller with Finite Response Time (Dead-Beat-Behavior). These controllers are able to adjust the controlled variables to the reference value after $n+1$ steps totally, where $n$ can be set to a positive number according to the dynamic requirements. This is described for any chosen $n$ by the following equation:

$\boldsymbol{\Psi}_{\mathrm{R}}^{\angle \mathrm{K}}(\mathrm{z})=\frac{1}{\mathrm{n}} \sum_{\mathrm{i}=2}^{\mathrm{n}+1} \mathrm{z}^{-\mathrm{i}} \cdot \boldsymbol{\Psi}_{\mathrm{R}}^{*} \angle \mathrm{K}(\mathrm{z})$ steady state in case of a permanent network frequency drop. Furthermore, the controller will work more accurate. With any other $\omega_{k}$, the variables of the controller change continuously.

Equation (21) means also, that both components of $\boldsymbol{\Psi}_{\mathrm{R}}^{\angle \mathrm{K}}$ are controlled independently, i.e. the control channels are decoupled.

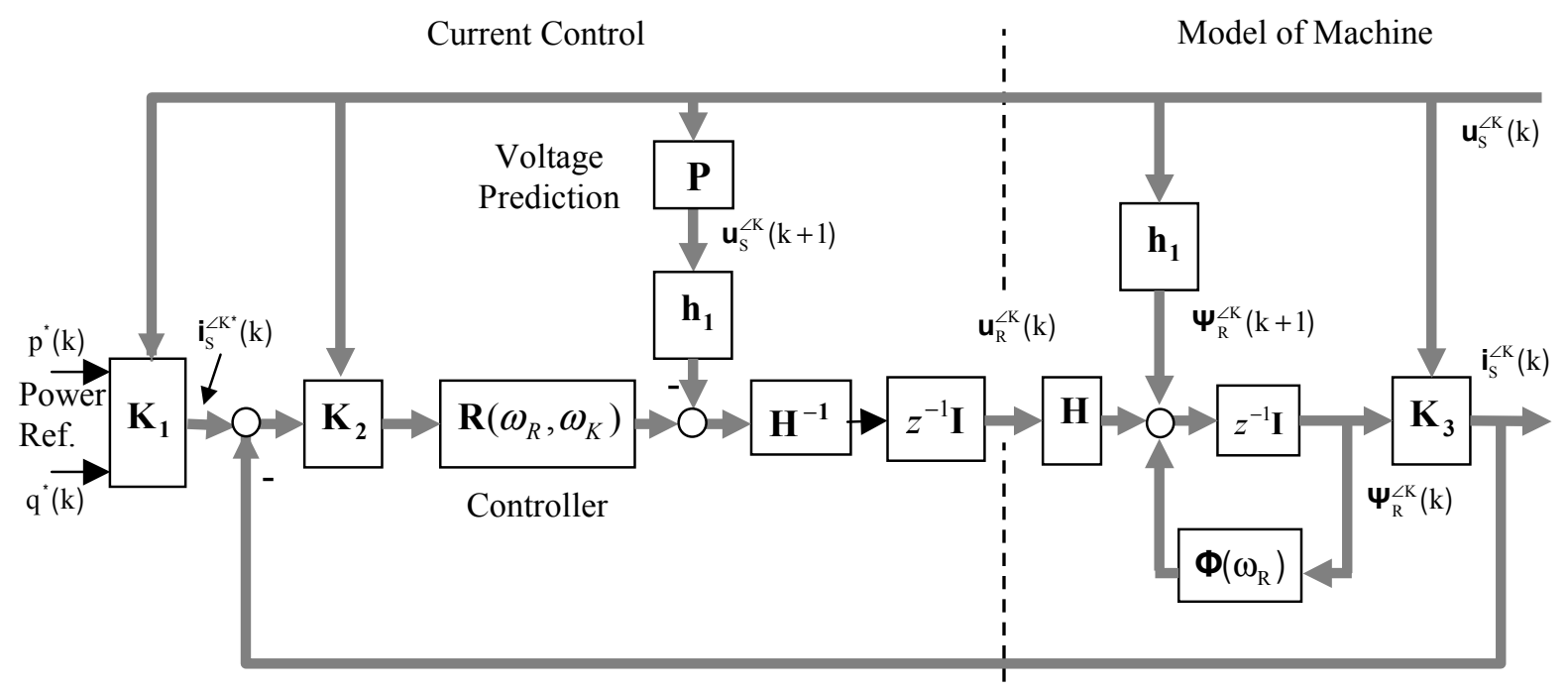

Fig. 1 Model of DFIM and corresponding controller

The corresponding controller for our application is then:

$$
\mathbf{R}_{\mathrm{n}}=\frac{1}{\mathrm{n}-\sum_{\mathrm{i}=2}^{\mathrm{n}+1} \mathrm{z}^{-\mathrm{i}}} \cdot\left(\mathbf{I}-\mathrm{z}^{-1} \cdot \boldsymbol{\Phi}\right)
$$

With increasing number of controls steps $n$, the controller will be more complex. However, the required control energy decreases if the control action is turned out in several steps. The choice of $n$ depends also on the sampling period of the particular application. Fig. 1 shows the controller and the machine model structure as well.

Because the rotor flux linkages are not measurable directly, the controller is extended by two blocks $\mathbf{K}_{\mathbf{2}}$ and $\mathbf{K}_{3}$, which are included for conversion between $\boldsymbol{\Psi}_{\mathrm{R}}^{\angle \mathrm{K}}(\mathrm{k})$ and $\mathbf{i}_{\mathrm{S}}^{\angle \mathrm{K}}$ based on Equation (11).

The reference signal $i_{\mathrm{S}}^{\angle \mathrm{K}^{*}}(\mathrm{k})$ is derived from the corresponding values of active and reactive power, which are the outputs of the second level controller. One of the main features of this controller is its ability to compensate stator terminal voltage changes. However, for this purpose we need $\mathbf{u}_{\mathrm{S}}^{\angle \mathrm{K}}(\mathrm{k}+1)$, which is unknown and therefore it must be predicted. According our experience, good results can be achieved by linear extrapolation from $\mathbf{u}_{\mathrm{S}}^{\angle \mathrm{K}}(\mathrm{k})$ described by the transfer function $\mathbf{P}=2-z^{-1}$.

The controller equations contain also $\omega_{k}$ as parameter, which is the speed of the reference frame. This parameter must be chosen properly. For $\omega_{\mathrm{k}}=\omega_{\mathrm{N}}$, where $\omega_{\mathrm{N}}$ is the average network frequency, all controller variables will remain in the

\section{CONTROL SCHEMES IN GENERATOR AND PUMP MODES}

In the previous section we discussed the core current (rotor flux linkage) control of the DFIM. This part requires reference values for stator active and reactive power as input. For an appropriate dynamic behavior of the unit, these values are not fixed, but they can vary in a specific range according to the network requirements. Furthermore, for secure and optimal operation the rotor speed must be controlled. This is carried out also by controlling the active power reference value. In generation mode, the hydraulic governor controls the rotor speed as well. Fig. 2 provides an overview about the entire control system. The structure and functionality differs slightly in generator and pump modes (Kuwabara, et al., 1994). The voltage and active power controller are working to the inputs of the stator current controller directly. The reference value of the active power regulator can be modified by the unit speed and network frequency controller as well. In generation mode, the electrical speed controller is activated only when an unreasonable speed deviation occurs. It makes sure that the speed is kept within the required range. In generation mode, the speed is controlled continuously by the speed governor, which works to the hydraulic wicket gate opening. With the network frequency control, the unit is able to participate in the primary control of the power system. In contrary to classical synchronous machine units, the control deviation is conducted, beside to the governor control, also to the active power controller, which works to the electrical rotor circuits. This regulator channel is much faster than 
those of the governor. However, the ancillary energy supplied to the network is charged by the kinetic energy of the rotor, which will be decelerated in the consequence. Therefore, it is necessary to replace the energy supply by the turbine after a short period of time. Nevertheless, DFIM units provide an excellent means for a fast power control.

In our application, the controlled power is that one on the network side, which is the sum of DFIM and inverter power. Because the current control is developed for the stator terminal quantities, the output of the power controller must be adjusted to the machine by subtraction of the current rotor power.

The used turbine model bases on the references (IEEE Committee report, 1973). This controller and the associated hydraulic equipments are also on classical hydro turbines existent and therefore, this topic will not be discussed here in detail.

\section{SIMULATION RESULTS OF THE GOLDISTHAL UNITS}

The investigations on the dynamic behavior of the new variable speed units were carried out in the preliminary project stages so that no proper specifications were available to the control concept and machine parameter. On the other hand, the interest was focused on the dynamic interaction between the variable speed units and the network. For this purpose, a model of DFIM and regulators described above was used. The electrical power system of the VEAG was modeled in detail together with other parts of the UCTE system. The full system consists of several hundreds synchronous generators and thousands of lines and nodes. Excitation and governor control of common power plants were considered by different models according to their real configurations. As simulation environment we used the program package PSD (FGH Mannheim, 2001). PSD was extended by a DFIM model while the

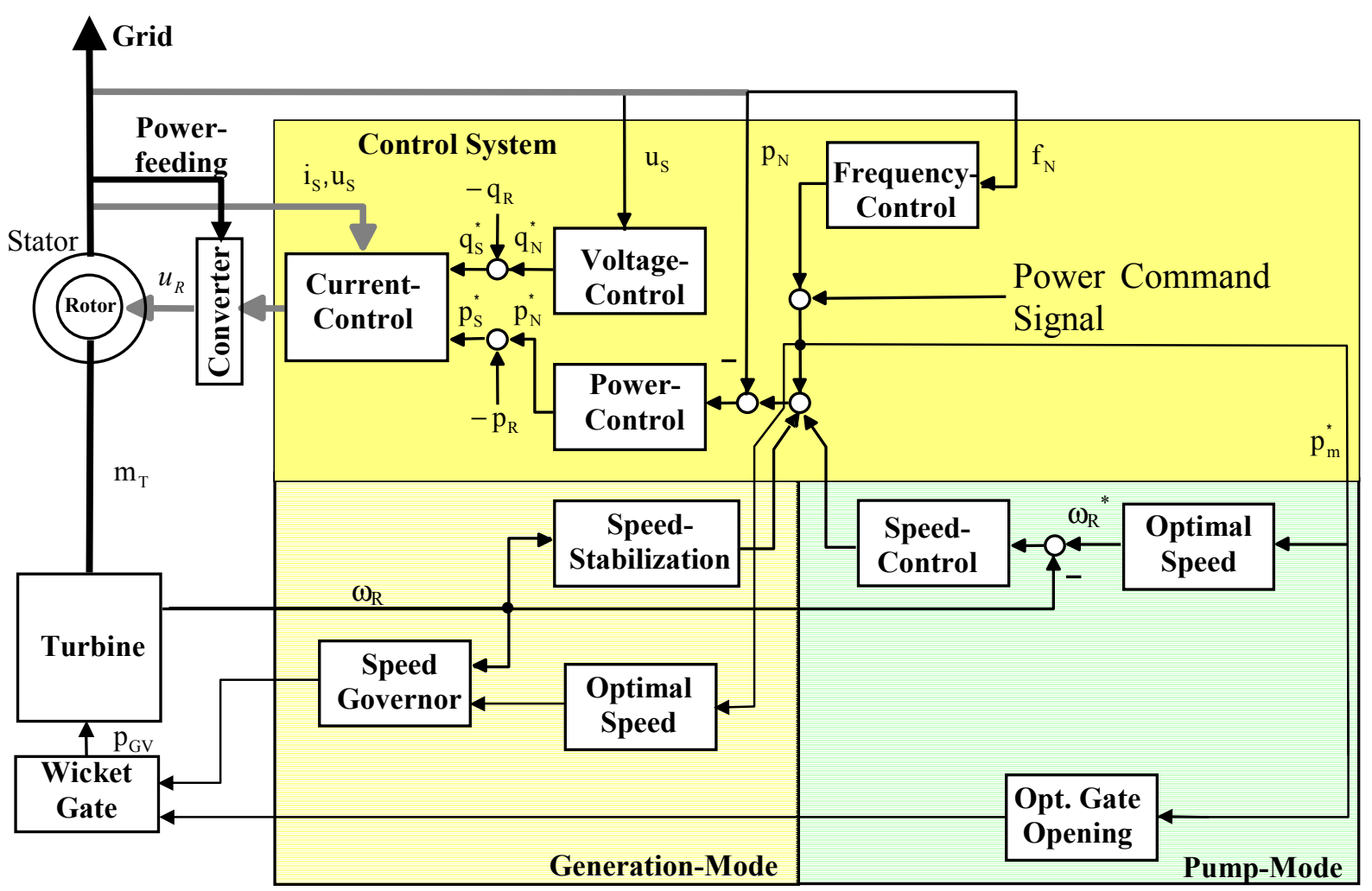

Fig. 2 Control system in generator and pump mode

The total power of the unit is consisting of the stator and rotor parts. In the simulation, no losses are assumed for the converter. Calculating the prefault steady state for the dynamic simulation, the total unit power calculated by a standard load flow program must be spited into these two parts. This can be carried out iteratively. We have implemented for this purpose a simplified Newton algorithm. The speed of the unit is set as an optimum for the given operating point and operating mode. To get the speed depending on the actual power, the water head, and the operating mode, a characteristic function describing the specific unit is used in the simulation. regulator part was described by the user defined block-oriented modeling technique.

The following simulation examples should demonstrate the dynamic capabilities of the units with DFIM drive in comparison with traditional synchronous machines. Fig. 3 shows results where a three-phase short circuit in a distance network location was simulated. In the consequence of the short circuit, the terminal voltage in Goldisthal breaks down to 0.7 p.u. approximately. During the short circuit period, synchronous machines cannot supply the full power into the network. Despite of the voltage drop of $20-30 \%$, variable speed units are able 
raising the active power back to the steady state value even in the short circuit period.

Conventional units will be accelerated in case of a network short circuit. This is due to the unbalance between electrical and mechanical torques. If the fault clearing time is to long, the synchronous machine exceeds the transient stability limit and goes over to asynchronous operation. According to the common practice, synchronous machines running asynchronously should be disconnected from the network because of the risk of damages in the unit.

DFIM drives cannot trip except limitations are reached in controllers or in the converter. Furthermore, due to the fast power activating capability of DFIM units they can improve the transient stability of other synchronous generators in the network. This is shown in Fig. 4. If in Goldisthal only synchronous machine drives are running, a generator in a distance of about $150 \mathrm{~km}$ trips following a short circuit. However, the system remains stable in case of DFIM drives. The transient stability will be generally improved by DFIM pump storage units. Furthermore, after the disturbance, with DFIM a normal operating point will reached much faster then in the case of synchronous machines.

Figure 5 should demonstrate the active power control capability of DFIM maintaining the frequency deviation in a smaller range after loss of generation power. With DFIM, the frequency drop is less. Even in pump mode, the units are able to support the system by activating more power. In generation mode, the speed governor and electrical power regulators are working parallel. Thus, a further improvement can be achieved.
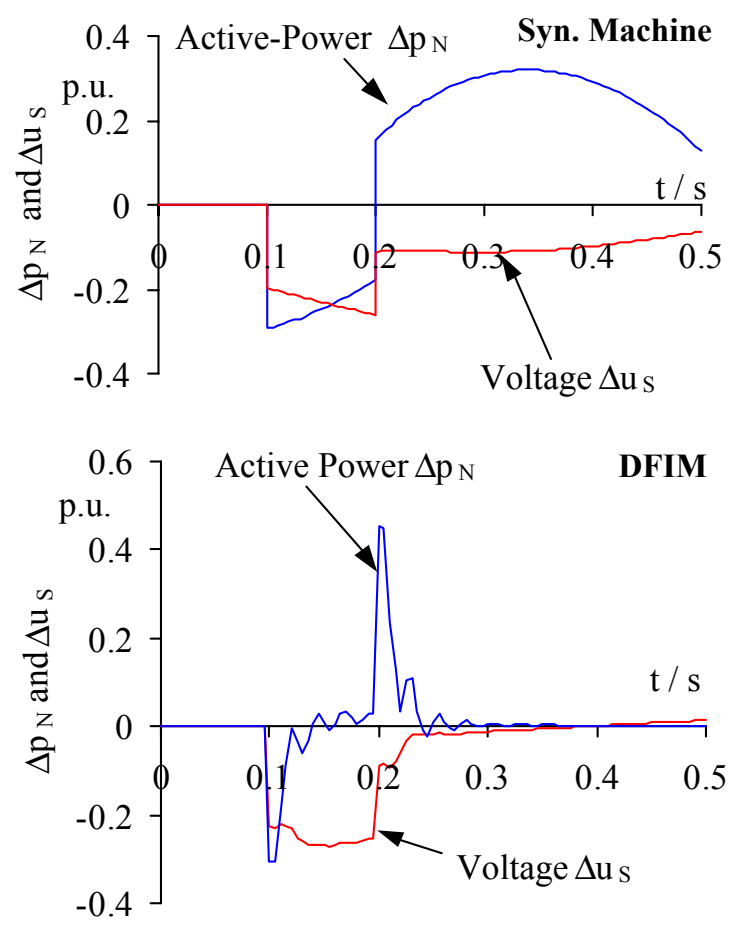

Fig. 3 Comparison of dynamic behavior of DFIM and Synchronous Machine drives during a network short circuit (pump mode)
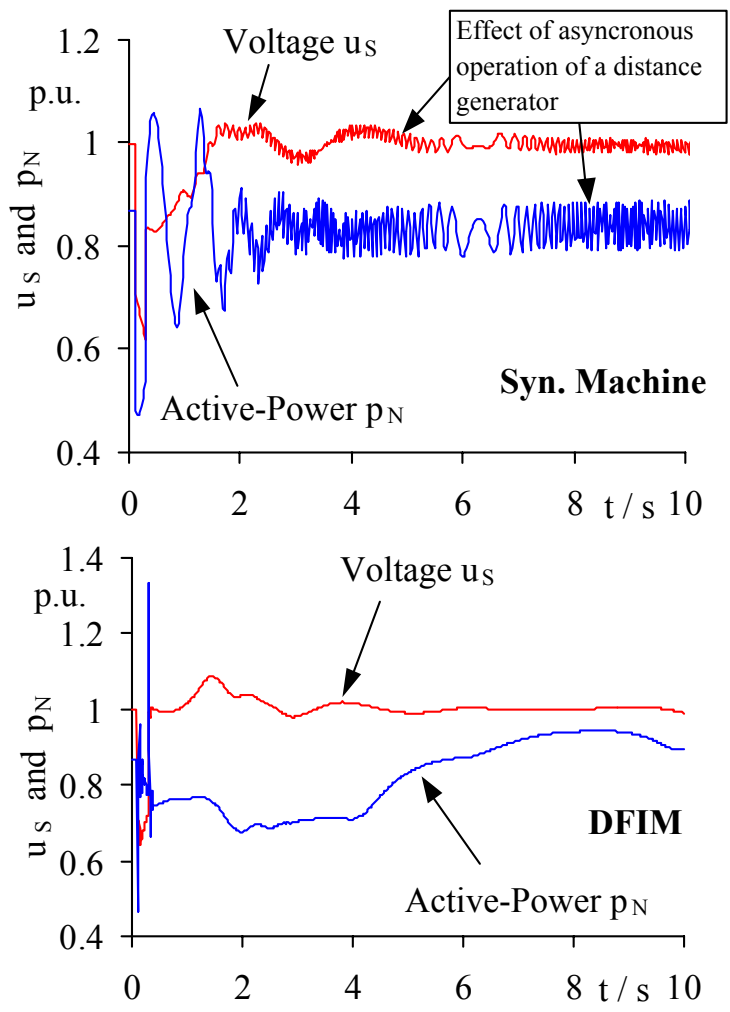

Fig. 4 Avoidance of transient instability of a distance generator following a network short circuit by DFIM drives (pump mode)
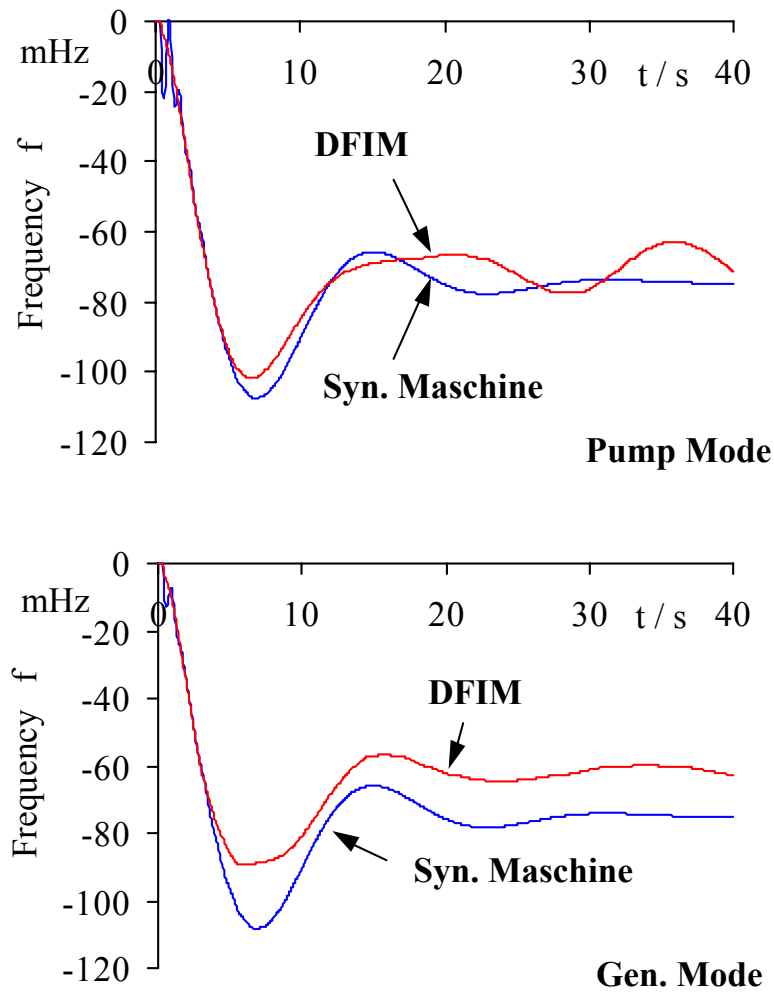

Fig. 5 Comparison of network frequency behavior with DFIM and Synchronous Machine drives following of a generation power loss in the power system 


\section{CONCLUSIONS}

Large pump storage power plants with variable speed drives can help to improve not only the efficiency of the units, but also they have a favorable effect on the dynamic behavior of electric power systems. DFIM provide the advantage of two electrical control channels from the rotor side, which allow to control active and reactive power independently. In this paper, a reduced order model for the simulation of multi-machine electric power systems comprising DFIM drives was developed. The model describes the DFIM on the same aggregation level as synchronous machine models established in the power system simulation practice. Thus, the calculation of large electrical power systems with variable speed pump storage drives becomes possible without considerable simplifications like the assumption of a single machine infinite bus system. The systematic design of a multivariable controller applied to the DFIM leads to a stator current controller with two channels, which are dynamically and stationary decoupled. Furthermore, the controller approach introduced in this paper allows the compensation of stator terminal voltage changes by predicting the voltage for the next step. The model, completed by voltage, power, speed, and network frequency as well as turbine controllers was used to simulate the dynamic behavior of the Goldisthal variable speed pump storage units in the interconnected German power system. The simulation results show that transient as well as frequency stability of the whole system can be improved by DFIM pump storage power plants.

\section{REFERENCES}

Bogenrieder W.; Lein G. (2000).

Leistungsfrequenzregelung mit

Pumpturbinensätzen variabler Drehzahl am

Beispiel des Pumspeicherwerkes Goldisthal

(Load-Frequency-Control of Pump Storage

Power Units in case of Goldisthal), VDI-Reports 1529, pp. 241 - 255.

Kundur, P. (1994). Power System Stability and Control, pp 170-173, Book, McGraw-Hill

Erlich, I. (1995). Analyse und Simulation des dynamischen Verhaltens von

Elektroenergiesystemen (Analysis and Simulation of the Dynamic Behavior of Electrical Power Systems), Habilitation-Thesis, Technical University of Dresden, Department of Electrical Engineering

Quang N.P. (1999). Praxis der feldorientierten Drehstromantriebsystemregelung (Paxis of the field-oriented drives control) Book, Expert Verlag

Kuwabara T.; Harada M.; Bando A. (1994). Performance of $400 \mathrm{MW}$ adjustable speed pumped storage unit for Ohkwachi power station, NE-Vol 15. Thermal Hydraulics of Advanced Steam Generation and Heat Exchangers ASME
IEEE Working Group (1973), Dynamic Models for

Steam and Hydro Turbines in Power System

Studies, IEEE Committee report, PES Winter

Meeting New York, pp. 1904 - 1915.

FGH Mannheim (2001). PSD Power System

Dynamics, Stabilitätsprogramm,

http://www.fgh-ma.de

\section{NOMENCLATURE}

H time-discrete control-matrix

h time-discrete disturbance-matrix

I unit matrix

$\underline{\underline{i}}_{R} \quad$ complex rotor-current

$\underline{i}_{\mathrm{s}} \quad$ complex stator-current

$\mathrm{k}$ sampling step

$\mathrm{k}_{\mathrm{R}} \quad$ coupling-factor

$1_{S} \quad$ stator-inductance

$1_{\mathrm{R}}$ rotor-inductance

$\mathrm{l}_{\mathrm{h}}$ main-inductance

$1_{\sigma} \quad$ leakage-inductance

$\mathrm{m}_{\mathrm{T}} \quad$ torque of turbine-shaft

$\mathrm{r}_{\mathrm{S}} \quad$ stator-resistance

$r_{R} \quad$ rotor-resistance

$\mathbf{R}$ control transfer function (matrix)

$\mathbf{R}_{\mathrm{DB}}$ control matrix, Dead-Beat-controller

$\mathbf{R}_{\mathrm{n}-2}$ control matrix, finite step response time

$\mathbf{R}_{\mathrm{n}-3}$ control matrix, finite step response time

$\mathrm{T}_{\mathrm{m}} \quad$ inertia constant

$\underline{\mathrm{u}}_{\mathrm{S}} \quad$ complex stator-voltage

$\underline{\mathrm{u}}_{\mathrm{R}} \quad$ complex rotor-voltage

$\mathbf{u}_{\mathrm{S}} \quad$ vector of stator-voltage

$\mathbf{u}_{\mathrm{R}} \quad$ vector of rotor-voltage

$\mathbf{x}$ state vector

$\mathbf{y}$ output-matrix of regulator

$z \quad$ z-operator

$\Phi$ discrete transition matrix

$\Psi_{\mathrm{R}} \quad$ complex rotor-flux-linkage

$\Psi_{S} \quad$ complex stator-flux- linkage

$\Psi_{\mathrm{R}} \quad$ vector of rotor-flux- linkage

$\boldsymbol{\Psi}_{\mathrm{S}} \quad$ vector of stator-flux- linkage

$\omega_{0} \quad$ synchronous angular velocity

$\omega_{\mathrm{K}}$ angular velocity of the reference frame

$\omega_{\mathrm{R}}$ angular velocity of rotor

$\omega_{\mathrm{N}} \quad$ power system network angular velocity

\section{Superscript}

$\angle \mathrm{K} \quad$ labeling variables in with $\omega_{\mathrm{K}}$-rotating reference frame

$\angle \omega_{0} \quad$ synchronous rotating reference frame

* labeling of reference values

, transient variable

\section{$\underline{\text { Subscript }}$}

d d-axis of rotating reference frame

q q-axis of rotating reference frame

$\mathrm{R}$ rotor variable

S stator variable

$\mathrm{T}$ turbine 